\title{
PERENCANAAN DAN PEMBUATAN PROGRAM SISTEM AKSES NILAI MAHASISWA MELALUI TELEPON
}

\author{
DESIGNING AND CONSTRUCTING STUDENT'S GRADE POINT \\ ACCESS PROGRAM VIA TELEPHONE
}

\author{
Mas Eko Prihantono, Vidian Prakasa Arianto, Nana Ramadijanti \\ Jurusan Teknik Telekomunikasi, Politeknik Elektronika Negeri Surabaya \\ Institut Teknologi Sepuluh Nopember \\ Kampus ITS, Keputih Sukolilo, Surabaya 60111 \\ Telp. (+62)-31-5947280 Fax. (+62)-31-5946114 \\ e-mail : $\underline{\text { mas_echo@yahoo.com, vidian_ari@lycos.com, nana@eepis-its.edu }}$
}

\begin{abstract}
ABSTRAK
Kebutuhan akan layanan dibidang pendidikan yang cepat, mudah, dan cermat saat ini dirasakan perlu kehadirannya, oleh karena itu diperlukan adanya suatu sistem atau alat yang memudahkan mahasiswa untuk mengetahui nilai mata kuliahnya dan Indeks Prestasinya diakhir semester.

Sistem Akses Nilai Mahasiswa melalui Telepon adalah suatu solusi untuk hal tersebut, Dengan meghubungi nomer Telepon jasa layanan ini mahasiswa dapat mengetahui nilai tiap-tiap mata kuliahnya dan Indeks Prestasi semesternya hanya dengan memasukkan memasukkan NRP nya dan memilih menu-menu yang disediakan oleh PC hanya dengan cara menekan tomboltombol yang telah ditentukan pada pesawat telepon.
\end{abstract}

Kata kunci : Sistem Telepon, DTMF (Dual Tone Multi Frequency), Sistem Interface, Sistem Database, SQL (Structured Query Language), Tabel, Query, Voice Modem, Perintah AT

\section{ABSTRACT}

Nowadays, the human's needs, especially in the education service need immediately, easily, and properly service. Because of those reasons, it's very important to make a system that can help college students to know their mark and GPA in the end of semester. The Student's Grade Point Access Program Via Telephone is the way to solve the problems. By calling this service's telephone number, students can know their grade points in every subject and their grade point average in this semester, by entering their students number (NRP) and choosing the menus that provide by software system, by pressing the button on the telephone.

Keywords : Telephony System, DTMF (Dual Tone Multi Frequency), Interface System, Database System, SQL (Structured Query Language), Tabel, Query, Voice Modem, AT Command.

\section{PENDAHULUAN}

Dewasa ini telah banyak sistem pelayanan telekomunikasi yang dapat dimanfaatkan oleh publik, antara lain sistem layanan tagihan telepon lokal atau interlokal, sistem informasi (109), serta layanan di bidang pendidikan.

Selama ini apabila mahasiswa ingin melihat nilai akhir mata kuliah tiap akhir semester maka mahasiswa harus datang ke kampus, sedangkan nilai tersebut keluar pada saat mahasiswa libur, yang menimbulkan kesulitan bagi mahasiswa yang berdomisili di luar kota. 
Pada proyek akhir ini dibuat aplikasi untuk mengolah nilai mahasiswa, sehingga mahasiswa dapat mengakses nilai akhir mata kuliah semester dan indeks prestasi semester (IPS) melalui telepon.

\section{KONFIGURASI SISTEM}

Pada perencanaan sistem ini diperlukan adanya sebuah voice modem yang berfungsi sebagai media interface antara line telepon dan PC dan juga sebagai pendukung proses otomatisasi dari sistem ini. Selain itu juga digunakan untuk memasukkan data-data masukan dari penekanan nomer telpon.

Perangkat lunak pada sistem ini merupakan otak dari seluruh proses. Perangkat lunak akan mengolah data-data dan inputan yang telah dimasukkan oleh pengguna (mahasiswa) untuk kemudian dianalisa secara software, sehingga didapat output berupa nilai tiap-tiap mata kuliah dan indeks prestasi semester (IPS) dari mahasiswa yang bersangkutan. Pada perangkat lunak ini dibuat suatu sistem database yang terdiri dari 3 macam tabel yaitu tabel nilaimahasiswa.db, tabel daftarkuliah.db dan tabel namamahasiswa.db.

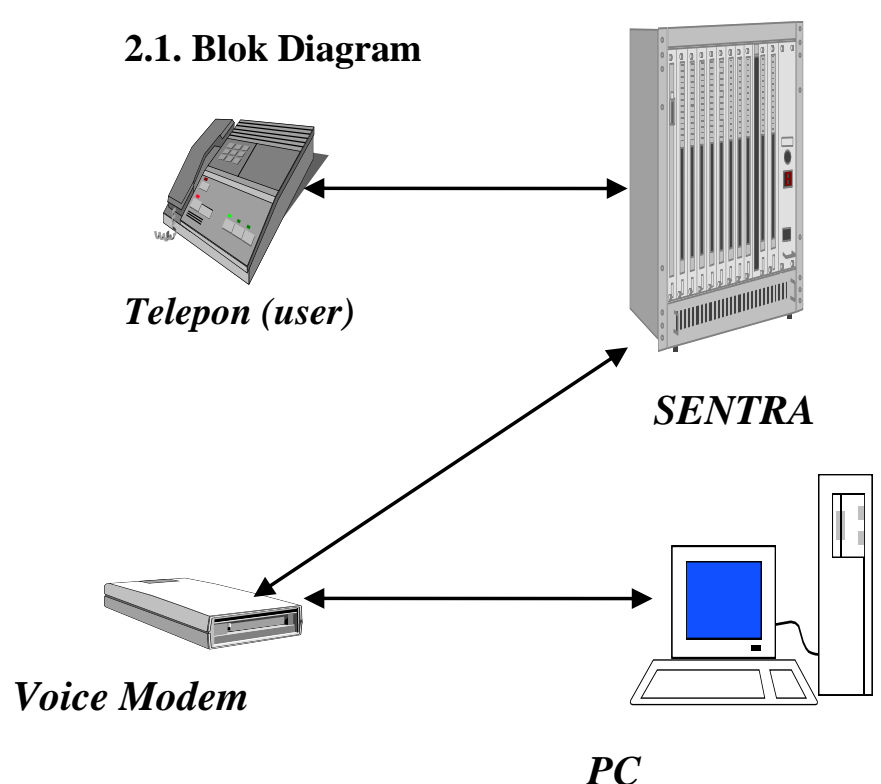

Gambar 2.1 Blok Diagram Sistem Layanan Akses Nilai

\subsection{Perangkat Lunak}

Perangkat lunak terdiri atas program utama dan beberapa sub rutin

\section{- Program Utama}

Program utama ini berisi inputan NRP, jika NRP yang dimasukkan benar maka akan berlanjut ke unit pilihan, jika NRP salah, maka akan dikeluarkan dari sistem.

- SubProgram Komunikasi Modem

Merupakan sub program yang berfungsi untuk mengatur segala komunikasi antara PC dengan voice modem. 
- SubProgram Pilihan

Merupakan inti dari pemrosesan database, dimana Berisi pilihan untuk memilih jenis layanan yang diminta, pilihan "1" untuk mengetahui nilai tiap-tiap mata kuliah, pilihan "2" untuk mengetahui nilai indeks prestasi semester, dan pilihan "3" untuk keluar dari sistem.

- SubProgram Nilai Mata Kuliah

Merupakan hasil pemrosesan dari unit pilihan, dimana setelah diproses oleh unit pilihan, maka hasil dari piliah "1" pada unit pilihan yang berupa tabel yang berisi nilai tiap mata kuliah dari mahasiswa yang bersangkutan akan ditampilkan. Dan juga terdapat pilihanpilihan, yaitu "1" untuk kambali ke unit pilihan, dan "2" untuk keluar dari sistem.

- SubProgram Indeks Prestasi

Merupakan unit untuk menampilkan hasil dari pilihan "2" pada unit pilihan, dimana tampilannya hanya berupa nilai indeks prestasi semester yang diproses (dihitung) pada unit pilihan. Juga terdapat pilihan yang sama seperti pada unit nilai.

\subsection{Flow Chart Sistem}

Adapun flow chart dari sistem digambarkan sebagai berikut : 


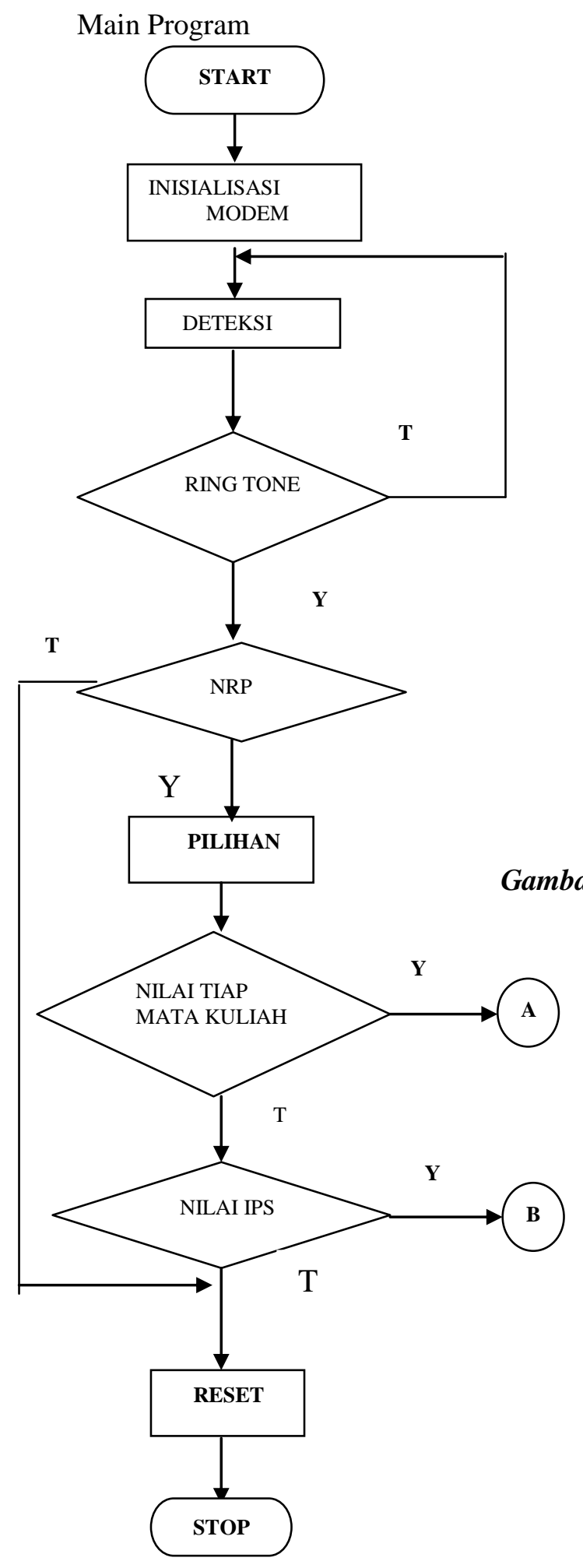

Prosedur Nilai Matakuliah

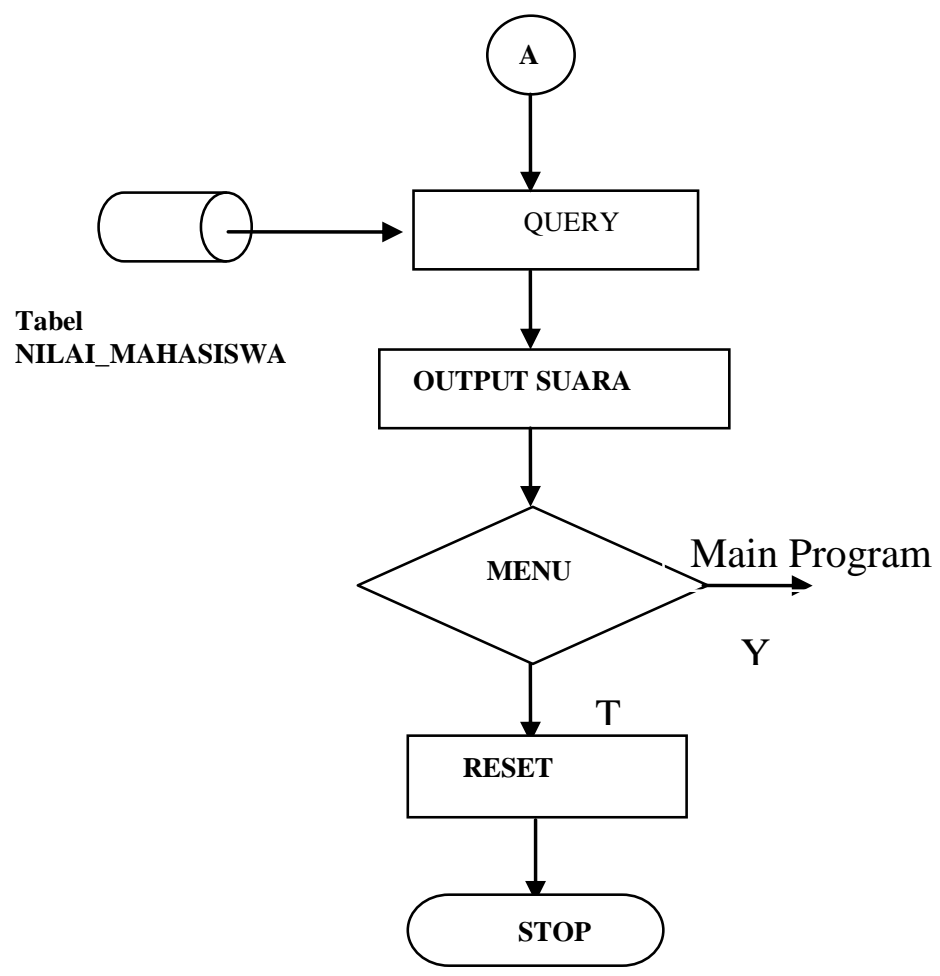

Gambar 2.3 Flowchart Procedure Nilai Mata Kuliah

Gambar 2.2. Flowchart Main Program 


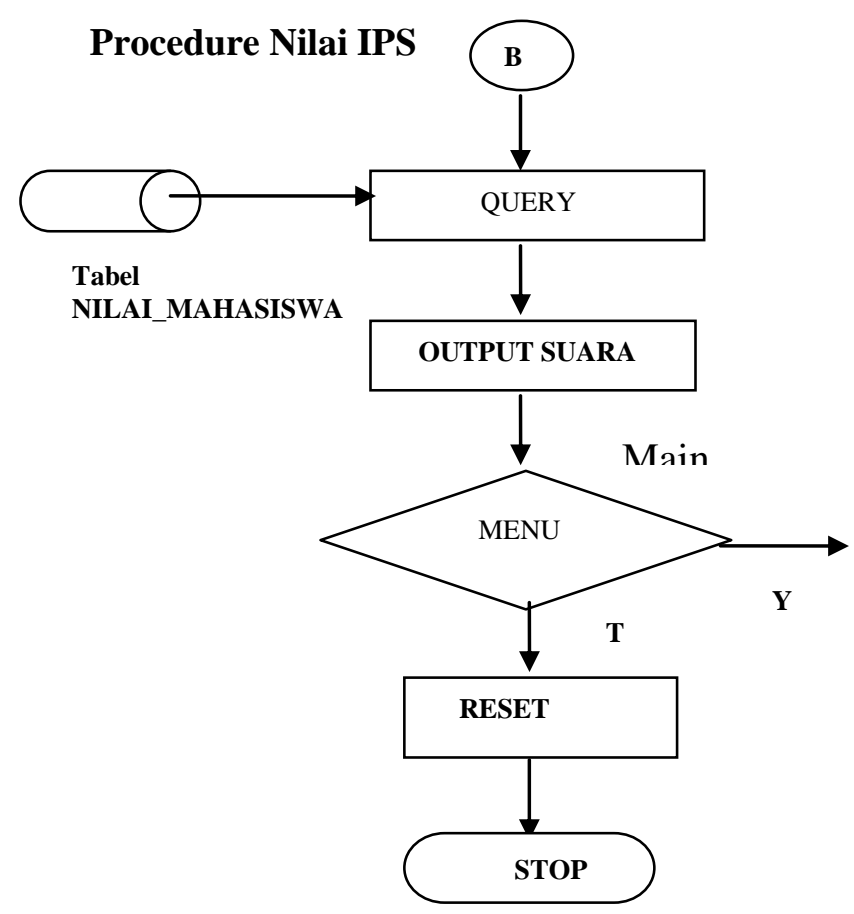

Gambar 2.4 Flowchart Procedure Nilai IPS

\section{ANALISA PROGRAM}

Program layanan yang kami buat ini terdiri dari beberapa form (tampilan), dimana formform tersebut memiliki fungsi-fungsi tersendiri. Form-form tersebut adalah :

\section{Form Komunikasi Modem}

Pada form tersebut dapat dilakukan segala monitoring dan manipulasi hubungan antara komputer dengan telepon,yang dilakukan oleh modem.

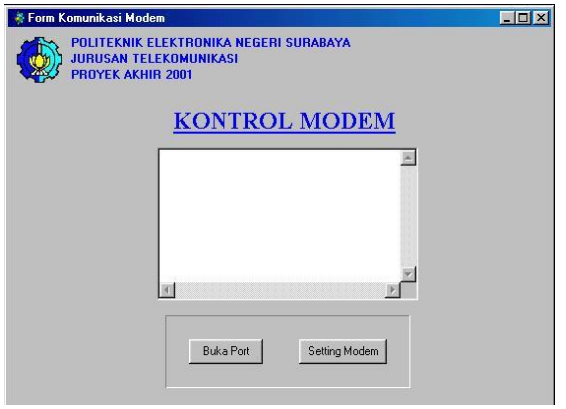

Gambar 3.1 Form Komunikasi Modem

\section{Form Depan}

Form ini memiliki kotak edit, dimana kotak edit ini akan menampung inputan NRP yang dilakukan oleh user melalui pesawat telepon. Untuk kemudian dideteksi oleh event On Timer. 


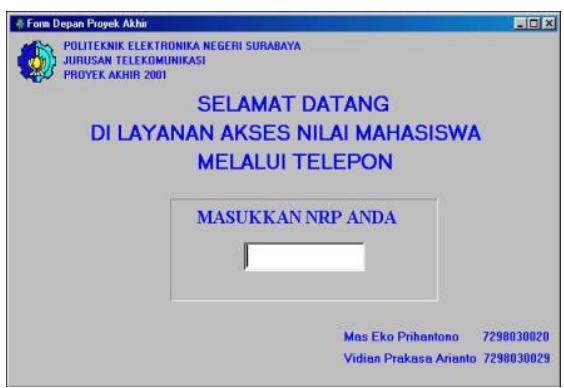

Gambar 3.2 Form Depan

\section{Form Pilihan}

Apabila NRP yang dimasukkan pada form depan terdapat pada database, maka proes berlanjut pada Form pilihan, dimana user akan diberi instruksi untuk memasukkan nomor menu untuk menggunakan layanan akses nilai mahasiswa. Layanan yang ditawarkan antara lain :

Untuk mengakses nilai tiap mata kuliah.

Untuk mengakses nilai IPS

(Indeks Prestasi Semester).

Keluar dari layanan.

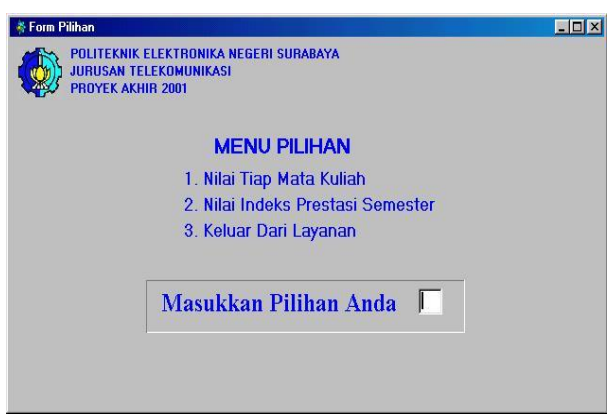

Gambar 3.3 Form Pilihan

\section{Form Nilai Mata Kuliah}

Merupakan tampilan jika kita memilih pilihan "1" pada form pilihan. Pada form ini akan ditampilkan tabel berisi nilai-nilai dari mahasiswa yang bersangkutan. Juga akan ditampilkan pilihan-pilihan berikutnya yaitu :

1. Untuk kembali ke form pilihan

2. Keluar dari layanan.

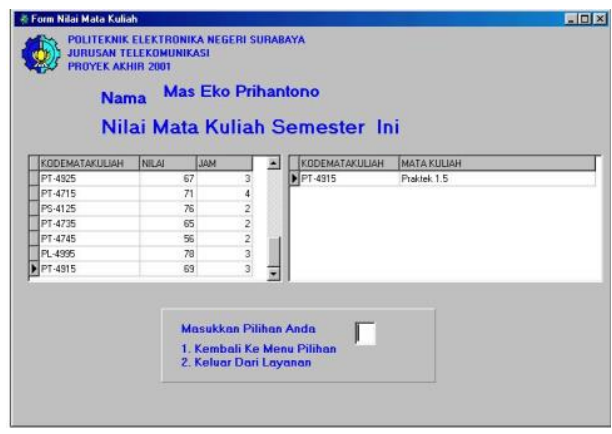

Gambar 3.4 Form Nilai Mata Kuliah 


\section{Form Indeks Prestasi Semester}

Merupakan tampilan jika kita memilih pilihan "2". Tampilannya berupa nilai Indeks Prestasi Semester dari mahasiswa yang bersangkutan. Juga terdapat pilihan-pilihan yang sama seperti pada form Nilai Mata Kuliah.

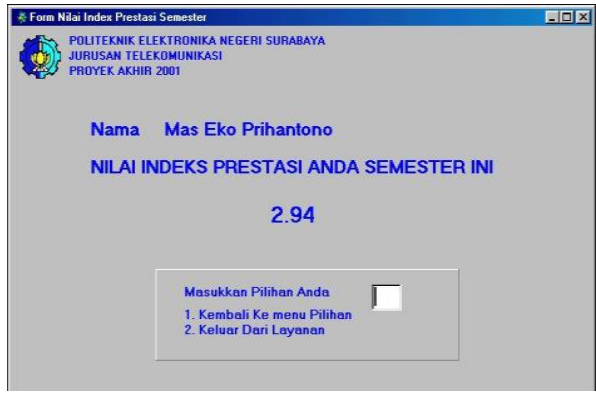

\section{Gambar 3.5 Form Nilai Indeks Prestasi Semester}

\section{KESIMPULAN DAN SARAN}

\subsection{Kesimpulan}

Sistem Layanan Akses Nilai Mahasiswa Melalui Telepon dirancang dan direalisasikan dengan menggunakan PC sebagai operatornya. Dari realisasi tersebut dapat diambil beberapa kesimpulan sebagai berikut :

1. Sistem interface antara line telepon dengan PC dapat berjalan sesuai rencana, sehingga segala fungsi yang terdapat pada voice modem dapat berjalan dengan baik, karena voice modem dapat menjalankan perintah-perintah yang diberikan.

2. Voice modem dapat mendeteksi sinyal DTMF yang diterima dan mampu mengeluarkan suara melalui line telepon.

3. Sistem database dapat berjalan sesuai rencana, karena mampu menginisialisasi dan menjalankan query, sehingga dapat mengolah database yang diinginkan.

4. Software dapat mengakses file-file suara yang disimpan dalam file-file berekstensi wav.

5. Proses pengolahan nilai dilakukan dengan menggunakan SQL (Structure Query Language) yang melibatkan tiga tabel yaitu tabel nama mahasiswa, tabel daftar kuliah , dan tabel nilai mahasiswa.

6. Sistem mampu melakukan pengolahan nilai untuk mahasiswa jurusan telekomunikasi kelas 3 baik reguler maupun ekstension.

7. Hasil pengolahan nilai memberikan 2 (dua) hasil, yaitu nilai tiap mata kulaiah dan niai Indeks Prestasi Semester, sesuai dengan NRP mahasiswa yang bersangkutan.

\subsection{Saran}

Sistem Layanan Akses Nilai Mahasiswa Melalui Telepon masih memiliki banyak kekurangan-kekurangan yang masih harus diperbaiki, sehingga perlu diadakan perbaikan dan penyempurnaan penambahan fasilitas baik di sisi sistem interface, perangkat lunak maupun data. Selain itu pengembangan dari sistem ini dapat dilakukan sehingga dapat diaplikasikan di bidang pendidikan, khususnya di kampus Politeknik Elektronika Negeri Surabaya. Penyempurnaan tersebut antara lain : 
1. Layanan ini bisa dikembangkan dengan melayani nilai seluruh mahasiswa politeknik. Untuk hal tersebut maka harus dikembangkan sustu teknik searching agar dapat melakukan pengolahan data dengan cepat.

2. Kualitas suara dan panjang suara yang dioutputkan ke line telepon dapat diperbaiki dengan menggunakan perangkat yang berkualitas baik dan perangkat lunak yang mampu memperbaiki kualitas suara, serta mengefektifkan file suara agar tidak terlalu panjang

\section{DAFTAR PUSTAKA}

1. Antony Pranata, Pemrograman Borland Delphi, Andi, Yogyakarta, 2000.

2. Ir.Inge Martina, Delphi 4.0, Elex Media Komputindo 1999.

3. Les Fred Dan Frank J Refler, Jr, Panduan Komunikasi Modem, Elex Media Komputindo 1994.

4. D C Green, Komunikasi Data, Penerbit ANDI Yogyakarta 1995.

5. ---------, Data/Fax/Voice Modem Operation Manual, Rockwell International

6. Marco Cantu, Mastering Delphi 5, SYBEX 1999

7. M. Agus J.Alam, Belajar Sendiri Borland Delphi5.0, Elex Media Komputindo 2000.

\section{DAFTAR WEBSITE}

1. http : ॥www.delphi32.com

2. http : Nwww.delphicity.com

3. http : llwww.Delphi.com 